Brit. J. Ophthal. (1968) 52, 356

\title{
IRRIGATING SPECULUM*†
}

\author{
BY
}

\section{J. M. ELSBY}

Department of Ophthalmology, University of Liverpool

THIS speculum was designed to keep the cornea moist during light-coagulation of the retina.

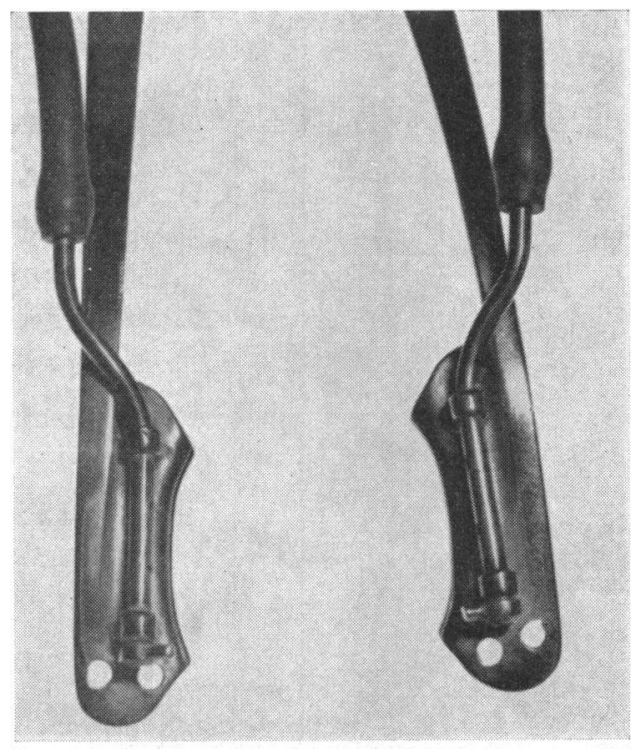

The metal tubes may be rotated so the holes are directed towards the apex of the cornea, which is usually between 5 and $10 \mathrm{~mm}$. above the level of the speculum. Rubber tubing is connected to a saline-filled syringe, and this is operated intermittently by an assistant.

The instrument was made by Messrs. J. Weiss and Son, Ltd., and the photograph prepared by Mr. W. Lee of the Central Photographic Service, University of Liverpool.

* Received for publication April 17, 1967

† Address for reprints and present address: Royal Isle of Wight County Hospital, Ryde. 